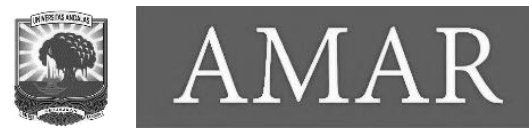

AMAR (Andalas Management Review)

Vol. 3, No. 1 (2019) page 77-102

The Management Institute, Faculty of Economics, Andalas University

ISSN (Print) 2476-9282 | ISSN (Online) 2548-155X

\title{
Bottom-Up or Top-Down, both Required Commitment
}

\author{
Renny Sukmono, Riani Budiarsih \\ Politeknik Keuangan Negara STAN \\ renny@pknstan.ac.id, riani.budiarsih@pknstan.ac.id
}

\begin{abstract}
One of the strategies of the Ministry of Finance is to encourage good budget management top-down by including the element of budget realization in setting the Key Performance Indicator (IKU). Determining the target budget of a year is top-down, while for budget withdrawal plan (prognosis budget) each month of the year is set bottom-up. This Prognosis budget is used as the target to be achieved by the working unit. The budget achievements show how much effort the work unit has made in achieving the targets they set themselves. Budget achievement is a comparison between the realization of the budget achieved and the target set. The smaller the budget achievement, it can be said that the commitment of the work unit to achieve the target is still low. In 2016, there are still a number of echelon I who still have a lot to do to increase this commitment. This is proved by the varying budget achievements that can be achieved by the echelon I. There is a work unit that has a very low budget achievement which is until the third quarter it only reaches $20 \%$ of the total budget, on the other hand, there is a work unit that is able to exceed the set target. Echelon I units that still have homework include Echelon I "B" and Echelon I "C". Difficulties in coordination with the lowest level units have indeed become one of the challenges for echelon I which have agencies spread throughout the territory of Indonesia. In addition, the characteristics of different work units are also a challenge for both to be able to impose equal treatment for all work units. Intensive and periodic monitoring from the top level is really needed to increase the commitment of lower-level work units. If the lower-level does not yet have a high commitment, it is impossible for the organization's main goal to be achieved.
\end{abstract}

Keyword: prognosis budget, budget realization, budget achievement, commitment, Top-Down, Bottom-Up

\section{INTRODUCTION}

\subsection{Background}

Modern organizations demand the provision of assignments and clear roles for each employee in achieving organizational goals. The aim of the organization will be not achieved without cooperation and synergy among its members. All elements contained in the organization have specific roles and tasks in achieving goals. Clear tasks and roles that will 
encourage ownership for each employee, which will be expected to encourage employee performance, which in turn encourages organizational performance.

Determination of tasks and roles in achieving organizational goals within the Ministry of Finance is included in employee performance contracts. Employee performance contracts contain key performance indicators that must be completed by employees within a budget year. The performance measurement used by the Ministry of Finance is the Balanced Scorecard (BSC) since 2007. Performance measurement is intended so that the achievement of organizational goals can be done effectively and efficiently.

Basically the BSC of the Ministry of Finance must be cascaded to all units below. The BSC of the Ministry of Finance is called Kemenkeu-wide. After being cascaded to the organizational units below, namely echelon I called Kemenkeu-One, to echelon II called Kemenkeu-Two, to echelon III called Kemenkeu-Three, to echelon IV called Kemenkeu-Four and to the level of executives called Kemenkeu-Five. The cascading method used in the Ministry of Finance is the Top-Down Method. This method is designed to connect Strategic Objectives (SS), IKU, and strategic initiatives between the highest levels of the organization with levels below it to the individual level. A cascading process is carried out with two events, namely direct method and indirect method. The Direct Method is done directly by making the SS, IKU, and strategic initiatives of the unit, so that both definitions, naming the SS, IKU and strategic initiatives are the same in the two units. This also applies to the achievement targets of IKU. Whereas indirect methods for all higher organizational targets are divided up into the units below in proportion to each unit.

There are five perspectives in the Ministry of Finance BSC, namely stakeholder perspective, customer perspective, internal business process perspective and learning and growth (LNG) perspective. The stakeholder perspective and LNG perspective are often discussed in the routine agenda of discussion on the performance of the Ministry of Finance. In the LNG perspective, IKU regarding budget realization is a topic that is always discussed. This shows that budgeting plays an important role in achieving organizational goals.

Budgeting is a quantitative plan of organizational operations that includes financial and non-financial aspects (Blocher, Chen, and Lin, 2000). Quantitative plans are plans expressed in 
terms of numbers (Winardi, 1996). Budget is a tool for management. The effectiveness of the implementation of the budget will be realized if supported by human resources from the internal environment of the organization, which has the same interest in achieving goals for managers and employees (Eris Dianawati, 2009).

Budgeting can be done with a bottom up and / or top down approach (Chandra, 1992). Bottom up approach (participation) is very possible for negotiations among managers to achieve organizational goals. According to Welsch (1998), the participation of middle and lower managers in budgeting will provide benefits namely reducing information inequality in the organization and giving rise to greater commitment to managers to implement and meet the budget. Commitment according to Shaub, Finn and Munter (1993) is the intensity of a person to identify himself, as well as the level of involvement in an organization or profession. With the commitment, it will encourage serious efforts to implement and achieve the agreed budget targets. Achieving a budget target is the achievement of an organization considering the organization's goals will not be achieved if there is no budget.

Budgeting planning within the Ministry of Finance is also done in a bottom-up manner. Each of the smallest work units proposes a budget requirement for its unit, then it will be united with the unit above to be submitted for its budget. Whereas the target for budget realization for each unit within the Ministry of Finance is done in a top-down manner. The target for the highest unit equals to the lowest target unit. This encourages all units to be able to meet the set targets. Actually this is something that will not be difficult because the proposed budget is proposed by the unit itself. However, the commitment is needed from all parties so that the budget is realized in accordance with the plan. Commitment to the budget in smaller units will greatly determine whether or not the budget target is reached in the larger unit because the realization of the budget in the unit below will be calculated to be the realization of the upper unit budget. This research is intended to see how the commitment of budget implementation exists within the Ministry of Finance. Commitment is seen from the suitability of the realization of the budget with the target of the budget realization achieved. In addition, it will be known which units need to increase commitment to be able to reach the target. 
Andalas Management Review, Vol. 3 No. 1, 2019

\subsection{Organizational Commitment}

Eris Dianawati (2009) states that organizational commitment is defined as the relative strength of employees in defining their involvement in the organization. This is characterized by three parts, namely:

a. acceptance of organizational values and objectives;

b. readiness and willingness to strive earnestly on behalf of the organization; and

c. the desire to maintain membership in the organization (being part of the organization).

Whereas Steers (1980) defines organizational commitment as a sense of identification (trust in organizational values), involvement (willingness to try as well as possible for the benefit of the organization) and loyalty (the desire to remain a member of the organization concerned) expressed by an employee against his organization. Organizational commitment is a condition where employees are very interested in their goals, values and organizational goals. Gibson (1994) provides an understanding that employee commitment is a form of identification, loyalty, and involvement expressed by employees of the organization or unit.

Dongoran (2001) states that organizational commitment concerns both parties, namely organizations and members, to behave according to the organizational value system that is beneficial for the development and welfare of two parties in order to realize organizational goals. So that there is a mutually beneficial relationship between members and organizations, namely the willingness of members to accept the system and value of the organization, willingness to do organizational tasks in order to achieve organizational goals and willingness to remain members of the organization and on the other hand there is an organization's willingness to meet the needs of its members to be prosperous. Porter and Smith in Porter (1980) defines organizational commitment as a commitment to the organization as the nature of an individual's relationship with an organization that allows a person who has a high bond with the organization by showing behavior remains a member of the organization concerned, willingness to try as well as possible in the interests of the organization, trust and strong acceptance of the values and goals of the organization. Mowday, Porter and Steers stated that organizational commitment has three components, namely: 
a. Identification with the organization that is acceptance of organizational goals where this acceptance is the basis of organizational commitment. Employee identification is seen through the attitude of agreeing to organizational policies, the similarity of personal values and organizational values, a sense of pride being part of the organization.

b. Engagement according to the roles and responsibilities of work in the organization.

c. Warmth of affection and loyalty to the organization.

\subsection{Budgeting Participation}

Vroom in Mitsi Leung (1990) defines participation as a process of cooperation in making decisions by two or more groups that influence the decision making itself in the future. This participation is an action that involves subordinates in decision making, thus encouraging subordinates to contribute as much as possible to the achievement of goals.

Participation in budgeting is a process where managers at the upper and lower levels are involved in the process of preparing and determining their budget goals. Participation involves managers at the lower level because it will encourage a sense of responsibility to meet the targets or targets set in the budget. Participation is needed in the context of making joint decisions where all management ranks provide input or information in making decisions. If a subordinate participates in decision making, he will indirectly internalize the goal. Furthermore, it will be assumed that organizational goals are their own goals that must be achieved. Participation is needed in the context of making joint decisions where all management ranks provide input or information in making decisions. If a subordinate participates in decision making, he will indirectly internalize the goal. Furthermore, it will be assumed that organizational goals are their own goals that must be achieved.

The budget target is a challenging budget, but it can be achieved. According to (Blocher et al., 2000), the advantages of using the highest budget target that can be achieved are:

a. Increasing manager's commitment to achieving budget targets.

b. Reducing organizational control costs and manager's risks with regard to incomegenerating practices that harm or undermine corporate ethical standards.

c. Allows managers to act effectively and efficiently. 
d. Increase the benefits of the budget as a planning and coordination tool.

Whereas according to Anthony and Govindarajan (1998: 386-387), there are several reasons why senior management approves the budget that can be achieved as the budget target, namely:

a. If the budget goals / targets are too difficult to achieve, managers will be motivated to take short-term actions that allow them to ignore the company's long-term interests.

b. Budget targets that can be achieved reduce the motivation of managers to manipulate data in achieving budget targets.

c. When a manager can meet or exceed the target, there will be an atmosphere of "victory" and a positive attitude towards the company.

d. One limitation of the budget that can be achieved is the possibility that the budget target is met even though the manager does not make optimal efforts.

Blocher et al. (2000) state that there is no single characteristic that can define the success of a budget. The most important factor is the budget supported by key managers. A successful budgeting process is if managers realize that the budget is their own budget, not a separate part of the personal budget. Managers feel they have the budget and are trying to reach the budget target. To achieve budget success, managers must carry out the budgetary principle in managing the budget, namely planning, coordination and control. Another factor which is also a determinant of budget success according to Blocher et. al (2000) include:

a. Subordinates feel that the budget is a planning and coordinating tool to help them do their jobs better.

b. Successful budgeting is a tool to motivate people to work in such a way that it leads to organizational goals and improvements.

c. A successful budget if it contains information that is technically correct and contains accurate numbers.

\subsection{Performance Measurement}

The concept of Balanced Scorecard (BSC) was developed by Robert S. Kaplan and David P. Norton which began with a study of performance measurement in the business sector in 1990. BSC consists of two words, namely a scorecard and balanced. A score card is a card used 
to record the performance results of an organization or individual score. Score cards can also be used to plan scores that will be realized in the future. Through a score card, the score that will be realized by the organization / individual in the future compared to the actual work. The results of this comparison are used to evaluate the performance of the organization / individual concerned. The word balanced is intended to show that the performance of the organization / individual is measured in a balanced manner from two aspects namely financial and nonfinancial, short and long term, internal and external.

The preparation of the scorecard starts from the determination of the organization's vision and mission. Vision is a statement that describes the condition of the organization to be achieved in the future. While the mission explains how to do it as a manifestation of the predetermined vision. In the BSC concept, the vision and mission are formulated and translated into a number of strategic goals. Strategic goals are statements about what you want to achieve (strategic goals as output / outcome) or what you want to do (strategic objectives as processes) or what you should have (strategic objectives as input). To facilitate the organization in communicating its overall strategy to all members of the organization in order to succeed in achieving organizational goals, a strategy map was made. The strategy map is a dashboard that maps the organization's strategic goals in a framework of causal relationships that describe the overall course of the organization's strategy.

Kaplan and Norton use four BSC standards, namely financial, customer, internal business process and learning and growth. The financial perspective is used by stakeholders in order to assess organizational performance. In other words, this perspective reflects the organization must meet the expectations of stakeholders so that it is considered successful by stakeholders. The customer perspective is a customer-oriented perspective because they use the products / services produced by the organization. The internal business process perspective is a series of activities contained in the organization to create products / services in order to meet customer expectations. This perspective describes business processes that are managed to provide services and values to stakeholders and customers. The learning and growth perspective is a perspective that describes the ability of an organization to make improvements and changes by utilizing the organization's internal resources. Organizational sustainability in the long run depends heavily on this perspective. 
Further the strategy map is drawn up, then it is to determine the Key Performance Indicators (IKU) for each strategic goal. IKU is a measuring tool for achieving strategic goals. In the formulation of the IKU it should meet the characteristics of good and sufficient performance indicators, namely using the SMART-C principle, namely:

a. Specifically, IKU must be able to express something unique in assessing the performance of a work unit.

b. Measurable, IKU designed must be able to be measured clearly, have a unit of measurement, and also clearly how to measure it.

c. Achievable, the IKU chosen must be achieved by the person in charge or unit in charge.

d. Relevant, IKU selected and determined must be in accordance with the vision and mission, as well as the strategic objectives of the organization.

e. Time-bounded, the selected IKU must have an achievement deadline.

f. Continuous improvement, IKU is built to adjust to the development of the organization's strategy.

After determining the IKU for each strategic target, the organization needs to set targets for each IKU. Target is a measure to be achieved within a certain period of time. Regarding the application of BSC, targets are generally set for a period of one year. Determining the size of the target can be based on several things such as last year's achievement (baseline), stakeholder desires, or looking at the internal and external conditions of the organization.

\subsection{Budget Planning Entry List (DIPA)}

In the cycle of budget execution, Budget Users (PA) / Budget User Proxies (KPA) are tasked for preparing DIPA proposals based on budgeting documents (RKA-K / L) that have been ratified. DIPA is a document that is used as the basis for implementing state expenditure. In its implementation it is possible to revise the DIPA. Based on PMK No.15 / PMK.02 / 2016 concerning the Procedure for Budget Revision in 2016, PA / KPA can propose revisions and revise DIPA in accordance with the authority limits stipulated in the regulation. 
Based on DIPA, PA / KPA then prepares activity planning and identifies the needs of goods and services. Furthermore, the PA / KPA establishes a General Procurement Plan (RUP). The General Procurement Plan stipulated by PA / KPA consists of:

A. General procurement policies which include:
a. establish the model work;
b. ways of implementing Procurement;
c. organizing procurement; and
d. determination of the use of domestic products;

B. Budgeting plan for procurement costs and supporting costs,

C. Terms of Reference (KAK) which include:

a. description of activities to be carried out which includes background, intent and purpose, funding sources and other things needed;

b. the implementation time needed, including when the goods must be available at the location of the related activities / sub-activities, taking into account the deadline for the fiscal year / the effective deadline of the fiscal year;

c. technical specifications of work to be held; and

d. the total estimated cost of work.

The prognosis budget is a plan to withdraw funds every month.

\section{RESEARCH METHODOLOGY}

\subsection{Types and Data Sources}

The data used in this study are primary data sourced from the reports of the Directorate General of Treasury regarding the prognosis and realization of work units within the Ministry of Finance.

\subsection{Population and Samples}

The sampling technique used in this study is the Disproportionate Stratified Random Sampling technique. The population in this study is a work unit found in the Ministry of Finance. Each work unit is led by KPA. The number of the population is 1050 work units. Work 
units within the Ministry of Finance can be at the level of echelon I, echelon II, echelon III or echelon IV. Offices that have vertical agencies, usually have work units at the level of echelon II up to echelon IV.

To determine the number of samples, the authors used the Slovin formula:

$$
n=\frac{N}{1+N e^{2}}
$$

Description: $\mathrm{N}$ is the number of the population, $\mathrm{n}$ is the number of samples, and $\mathrm{e}$ is the leeway of inaccuracy because of errors that can be tolerated.

With a significance of $(\alpha)$ of 0.05 and a population of 1,050 people, the total number of 290 samples will be used in this study. For Echelon I which only has one DIPA, namely the Fiscal Policy Agency, the Director General of Budgeting, the Directorate General of Financing and Risk Management, the Directorate General of Fiscal Balance and the Inspectorate General, all included in the research sample. For other echelon I units that have several work units, the number of samples taken is proportional to the number of work units in each unit. The samples taken are presented in Table 1.

\section{Table 1}

\begin{tabular}{ccccc}
\multicolumn{5}{c}{ Number of Research Samples } \\
\hline Echelon I & Ec IV & Ec III & Ec II & Total \\
\hline A & & 2 & 2 & 4 \\
\hline B & & & 1 & 1 \\
\hline C & 54 & 95 & 9 & 158 \\
\hline D & 13 & 20 & 5 & 38 \\
\hline E & & & 1 & 1 \\
\hline F & & 42 & 15 & 57 \\
\hline G & & 18 & 4 & 22 \\
\hline H & & & 1 & 1 \\
\hline I & & & 1 & 1 \\
\hline
\end{tabular}




\begin{tabular}{|c|c|c|c|c|}
\hline Echelon I & Ec IV & Ec III & Ec II & Total \\
\hline $\mathrm{J}$ & & & 1 & 1 \\
\hline K & & & 1 & 1 \\
\hline L & & 4 & 2 & 6 \\
\hline \multicolumn{4}{|c|}{ Total } & 290 \\
\hline
\end{tabular}

Source: primary data

To see organizational commitment, especially regarding budget realization, the samples used are units other than echelon II. Darma (2017) states that the higher the level of the echelon, the lower the commitment to implement the budget. It takes commitment and coordination to reach the target organization. To see the commitment in the top leader which is supported by the commitment of the unit below, in this study using the subgroup control chart analysis method. The size of the subgroup used is 3 work units in each subgroup. Echelon I which only has one work unit, the echelon I is not included as analysis data. In addition, work units that have subgroup sizes of less than 3 are also not included as data to be analyzed.

\subsection{Average Control Chart and Standard Deviation}

Nowadays, Quality control is getting increased attention as a management tool by observing, evaluating, and comparing the important characteristics of a product with a standard form. An appropriate quality control program will improve product quality. One of the tools for quality control is a control chart. The control chart aims to determine the work results of a process can still be maintained at an acceptable quality level. Of course it becomes natural for each activity process to have diversity, namely diversity which is basically not important and the source cannot be regulated. However, on the other hand a process may experience diversity that can be categorized as serious. These sources of diversity may arise from various types of "recognizable causes" that are not random, such as officers' faults or machines that are not properly installed. A process that works in such a condition is called uncontrollable. A process that only experiences random diversity is said to be statistically controlled. 
Grouping the type of control chart depends on the data type. Gaspersz (1998) explains that in the context of statistical process control there are two types of data known, i.e:

1. Variable data is quantitative data that is measured for analysis purposes.

2. Attribute data is qualitative data that can be calculated for recording and analysis.

Based on these two data types, the type of control chart is divided into control charts for variable data and attribute data. Some control charts for variable data are control charts $\underline{X}$ and R. While the control chart for attribute data are control chart - p, control chart - np, control chart - c, and control chart - u. According to Gasperz (1998), in principle each control chart has:

\section{Central Line}

2. Upper control lines and Lower control line (one placed below the center line)

3. Distribution of quality characteristic values that describe the process. If the value is spread on the chart and is within the control limit without showing a certain tendency, then the process that is taking place is considered to be in statistical or statistically controlled. But if the values spread on the map fall or are outside the control limits or show a certain tendency, then the ongoing process is considered out of control (uncontrolled) so corrective action needs to be taken to improve the existing process.

The types of variable control charts are as follows:

\section{Control Chart $\underline{X}$}

$\underline{X}$ Control Charts or Average Control Charts, visualizing sample average fluctuations and averages of sample averages that show how the average sample deviations from the average. This deviation will give an idea of how consistent the process is. The closer the sample average to the average value then the process tends to be stable, otherwise the process tends to be unstable. The $\underline{X}$ Control Chart can be used to:

a. Monitor the changing in the distribution of an origin variable (in terms of its location).

b. Is the process still in the control line or not.

c. Is the average product produced in accordance with predetermined standards. 
The steps for making a Control Chart are as follows:

1. Determine the size of the subgroup;

2. Determine the number of subgroups;

3. Calculate the average value of each subgroup, namely $\underline{X}_{i}$;

$$
\underline{X}_{n i}=\frac{\sum X_{i}}{n_{i}}
$$

Where:

$\underline{X}_{n i}=$ Average $X$ value in the i sample subgroup

$\mathrm{n}_{\mathrm{i}}=$ number of samples in the i subgroup

$\sum \underline{X}_{i}=$ number of $X$ values in the i subgroup

Calculate the average value of all $\underline{X}$ that is the center line (CL), Upper Control Line (UCL) and Lower Control Line (LCL)

$$
\begin{aligned}
& \mathrm{CL}=\bar{X}=\frac{\sum \underline{X}}{N} \\
& \mathrm{UCL}=\bar{X}+\left(\mathrm{A}^{*} \underline{R}\right) \\
& \mathrm{LCL}=\bar{X}-\left(\mathrm{A} 2^{*} \underline{R}\right)
\end{aligned}
$$

Where:

$\mathrm{A} 2$ is the value of the constant and $\mathrm{R}$ is the average of the average range.

- Plot $\underline{X}$ on the $\underline{X}$ control chart, and observe whether it is in control or not.

\section{Control Chart R}

$\mathrm{R}$ (range) measures the difference between the lowest and highest values of the observed sample and provides an overview of process variability. The $\mathrm{R}$ control chart can be used to:
a. Monitor changes in terms of distribution;
b. Monitor the level of accuracy of the measured process.

The steps for making a Control Chart $\mathrm{R}$ are as follows:

- Determine the size of the subgroup; 
- Determine the number of subgroups;

- Calculate the difference between the largest and the smallest data from each subgroup, i.e:

$R=X_{\text {imaks }}-X_{\text {imin }}$

- Calculate the average value of all $R$, which is $R, R$ is the center line of the Control Chart $\mathrm{R}$

$\bar{R}=\frac{\sum \quad R}{N}$

- Calculate the control line for Control Chart R

$\mathrm{CL}=\bar{R}$

$\mathrm{UCL}=D 4^{*} \underline{R}$

$\mathrm{LCL}=\mathrm{D} 3^{*} \underline{R}$

Where D3 and D4 are fixed values.

Plot R data on Control Chart and observe whether the data is under control or not.

\section{RESULT AND DISCUSSION}

In this chapter will be discussed regarding analysis and discussion related to the prognosis budget prepared by the work unit, analysis and discussion regarding the realization that can be achieved by the work unit and analysis of the work unit's achievements. 


\subsection{Prognosis Analysis}

Table 2

Prognosis Average, Realization, and Achievement (in \%)

Work Unit Realization Achievement

Prognosis

(up to Q3)

(up to Q3) (s.d Q3)

\begin{tabular}{|c|c|c|c|}
\hline Ec Echelon II level & 57,6 & 52,19 & 90,33 \\
\hline Ec Echelon III level & 58,27 & 59,81 & 114,40 \\
\hline Echelon VI level & 57,9 & 62,03 & 118,58 \\
\hline
\end{tabular}

Source: primary data

Based on Table 2, it is known that each work unit, both the echelon II, III and IV level work units, sets a budget target that is not different, which is around $57 \%$. This is in accordance with the statistical tests conducted on the work unit prognosis data and the results of the tests in Table 2 are obtained.

\section{Table 3}

Prognosis Anova Test

\begin{tabular}{lccccc}
\hline Source & df & SS & MS & F & Sig. \\
\hline $\begin{array}{l}\text { Between } \\
\text { Groups }\end{array}$ & 2 & 0.002 & 0,001 & 0,707 & 0,494 \\
\hline $\begin{array}{l}\text { Within } \\
\text { Groups }\end{array}$ & 287 & 0,378 & 0,001 & & \\
\hline Total & $\mathbf{2 8 9}$ & $\mathbf{0 , 3 8}$ & & & \\
\hline
\end{tabular}

Source: primary data

Is there a difference in the average between echelon II, III and IV level work units, based on the results of the analysis it can be seen that there is no difference in prognosis between echelon II, III or IV level work units.

Budget absorption targets are set by each echelon I. This target is the IKU cascaded directly from the Minister of Finance's IKU. So that each unit under it must set the same target for their IKU target. The policy of setting the IKU target for budget absorption is top-down, 
meaning that the upper echelon units must challenge the lower echelon to be able to achieve the target so that the upper echelon targets are also achieved.

The budget prognosis is planning to withdraw funds from work units with monthly periods. Plans for withdrawal of funds are adjusted to the planned activities to be carried out by the work unit. Until now, there are still many work units that plan to withdraw funds that distend at the end of the fourth-quarter. This happens because some work units have substantial capital expenditures, in which the process for the realization of capital expenditure has a simple implementation stage. So that many work units are targeting the realization of capital expenditure at the end of the year. Seen in Table I both echelon II level units, echelon III and IV set targets for withdrawal of funds that are not high that is until the third quarter only targets funds withdrawal around 57\%. Even if it is calculated with a rough estimate, until the third quarter the work unit should have the courage to set a target of almost $75 \%$ of budget absorption. Caution in determining the target in this case is that the prognosis is indeed very logical because many things are unpredictable when they are achieved, for example in the process of procurement of goods and services which part of the process cannot be controlled by the work unit.

Based on the statistical process, the average prognosis prepared by echelon I units is statistically controlled. However, there is one observation that comes out of the control boundary, namely observation number 5 namely Echelon I "L". As can be seen in Figure 1, the compiled prognosis is above the upper control line. This shows that the prognosis prepared by Echelon I "L" can be said to be a challenging target. 


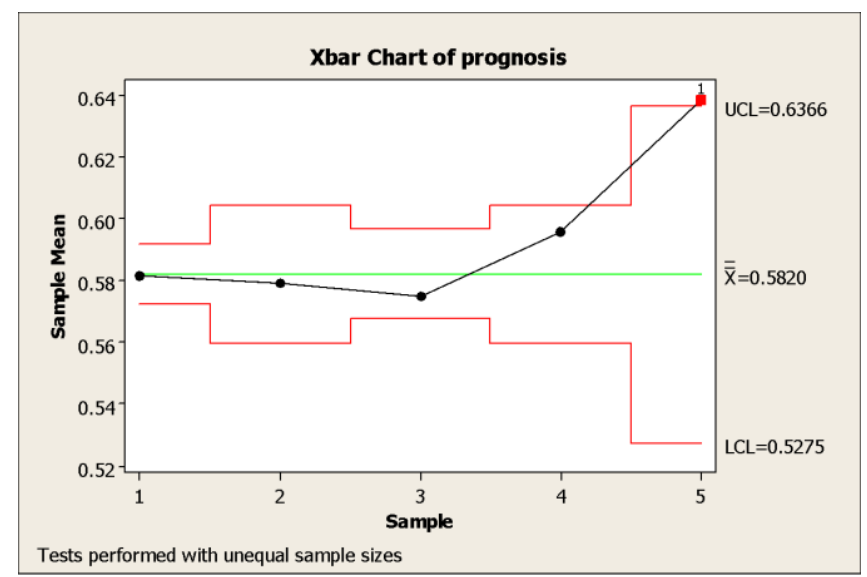

Figure 1. Control Chart for Average Prognosis of Echelon I

In addition to the average prognosis, it will also be seen how variability exists in echelon I units in preparing the prognosis, whether it can be homogeneous or not. In Figure 2 it will be explained how the variability of the prognosis in echelon I in the Ministry of Finance.

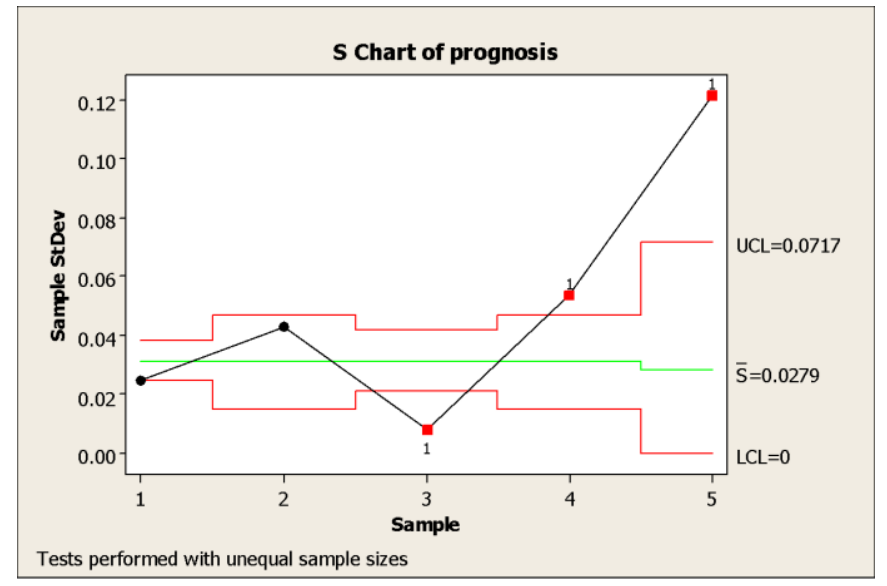

Figure 2. The Prognosis Variability in Echelon I

There are three echelon I units that exit the control boundary, namely observation 3 which is located below the lower control line, namely Echelon I "F" and two observations located above the upper control line, namely Echelon I "G" and Echelon I "L". Echelon I "F" has a small variability, meaning that between work units determine the prognosis that can be said to be homogeneous. When compared to the prognosis determined by other echelon I, the prognosis of Echelon I "F" is lower. For Echelon I "G" and Echelon I "L", have considerable 
variability, this indicates that the work unit in the echelon I environment sets different prognosis quantities.

To see commitment to the bottom-up and top-down mechanism, data will be seen in echelon I units that have Technical Implementation Units (UPT)s or vertical agencies in the region. To see this, the work units in echelon I units will be made into subgroups that are 3 working units in each subgroup.

The average prognosis prepared by work units in echelon I environments is shown in Figure 3.

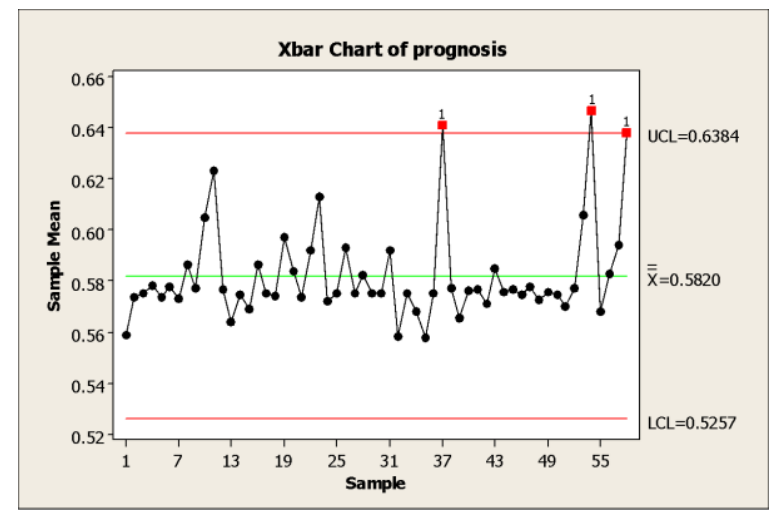

Figure 3. The Work Unit Prognosis Average Control Chart

There are three observations that come out of the upper control line, but this is a good point because the work unit dares to set challenging targets for the organization. Observations that come out of the upper control line include work units in the environment of Echelon I "D", Echelon I "G" and Echelon I "L". In Echelon I prognosis analysis, it is known that the homogeneous and insufficient prognosis occurs in the environment of Echelon I "F". Figure 4 shows that it turns out that the prognosis variability occurs in several work units in echelon I environments. 


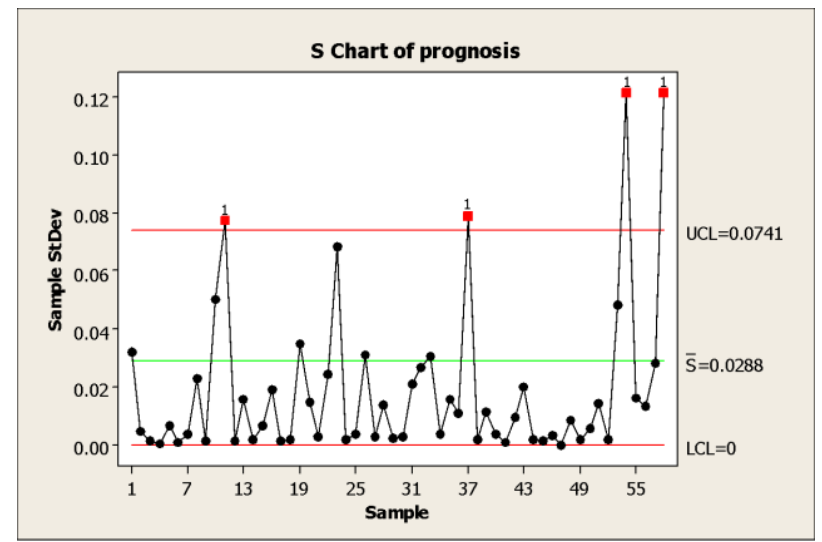

Figure 4. Work Unit Variability Control Chart

Challenging target setting does not only occur in work units in the environment "I" G and Echelon I "L", but also occurs in the environment of I "C" and "D" Echelon I. There are work units that set targets that are more challenging than the other work units. One reason that underlies challenging targets is the motivation of the work unit to make optimal efforts to achieve the target. A normal target will be achieved even though it is done with ordinary effort.

\subsection{Realization Analysis}

After the previous stage is analyzed the prognosis of echelon I budget and work unit, at this stage it will be analyzed how the realization of echelon I budget and work unit. Budget realization is how much the budget has been spent by the work unit to carry out its duties and functions. The realization data used is the percentage of realization of the allocated budget.

The average realization of echelon I budgets based on Figure 5 has been statistically controlled. This shows that the average realization of the echelon I budget does not exceed the control line. 


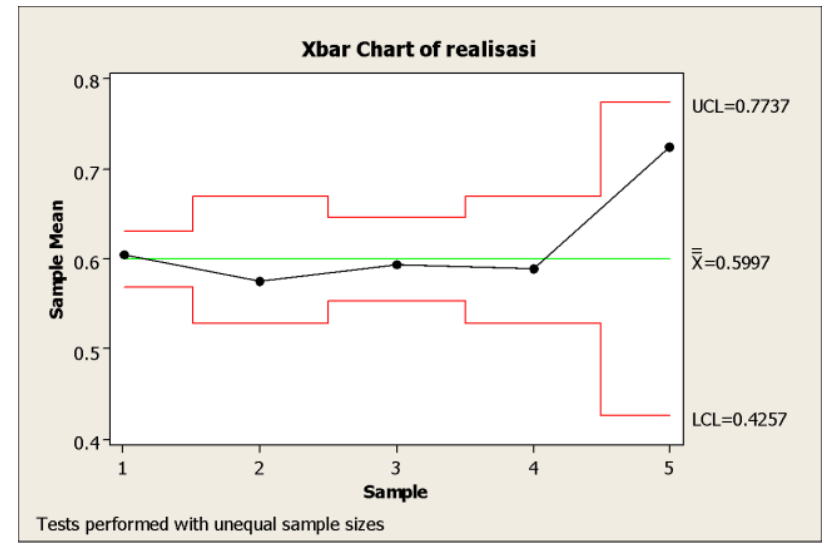

Figure 5. Echelon 1 Realization Average Control Chart

The average that does not exceed the limit of control can be caused by there is a large average realization capable of covering a small realization in one Echelon 1 unit. To see the commitment of each work unit in the echelon I environment whether it has controlled budget realization or not could be seen in Figure 6.

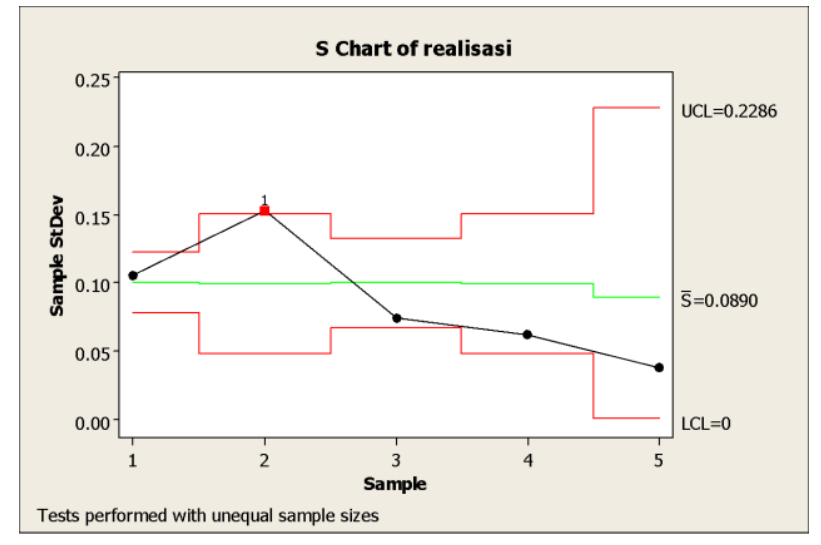

Figure 6. Echelon 1 Realization Budget Variability Control Chart

Figure 6 shows that there is one observation coming out of the upper control line. It shows that the echelon I has a very large variability in realization budget. There is a work unit that has a very large realization budget, on the one hand there is a work unit that has a very small budget realization. Observation that comes out is observation 2, namely Echelon I "D".

To see the commitment to the bottom-up and top-down mechanism, data will be seen in echelon I units that have Technical Implementation Units (UPT)s or vertical agencies in the 
region. To see this, the work units in echelon I units will be derived into subgroups that are 3 working units in each subgroup. This description will be seen in Figure 7.

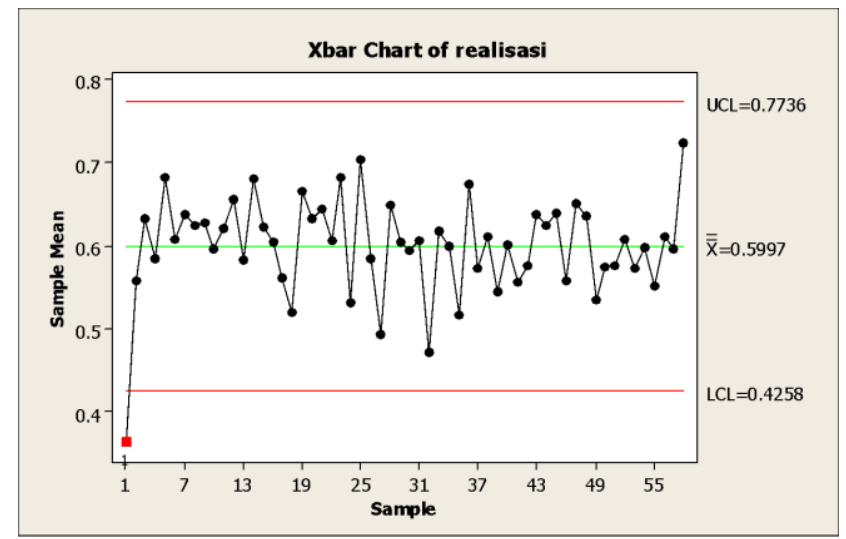

Figure 7. Work Unit Realization Budget Average Control Chart

Figure 7 shows that there is one observation that comes out of the lower control line, namely observation 1 . Observation 1 is a work unit located in the environment of Echelon I "C". There is a work unit that has a very low budget realization when compared to the realization of other work unit budgets.

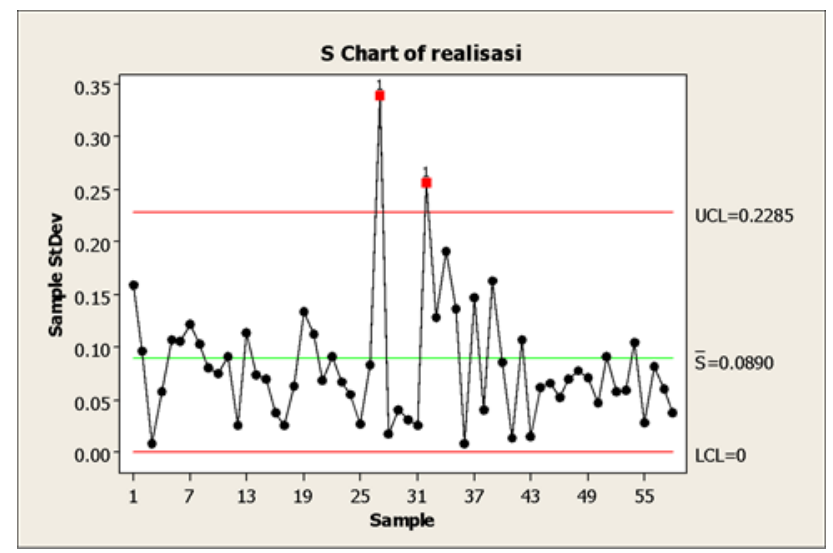

Figure 8. Work Unit Realization Budget Variability Control Chart

There are 2 observations coming out of the upper control line as seen in Figure 8 . These observations are observations 27 and 32, namely work units that are in the environment of Echelon I "C" and Echelon I "D", up to the third quarter of realization budget only reaching around $20 \%$ of the total budget. 


\subsection{Achievement Analysis}

Achievement is a comparison between realization budget and prognosis budget for a certain period. Achievements can show how much effort a work unit has in achieving the set targets. To see how the achievements in each echelon I unit, can be seen in how the average achievement and variability in the work unit in each echelon I.

The average achievement in echelon I units is statistically controlled, this is shown in Figure 9.

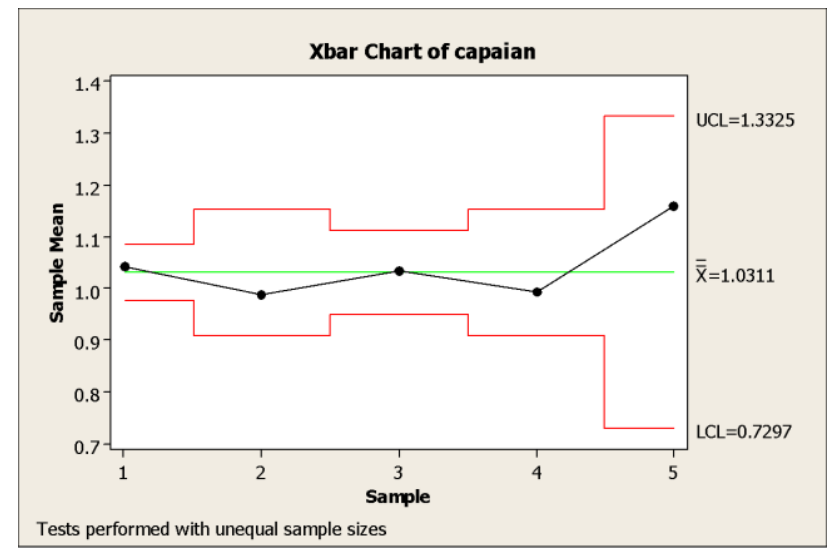

Figure 9. Echelon 1 Achievement Average Control Chart

There is no Echelon I average unit that comes out of the control line, this shows that echelon I has tried to achieve targets that have been set. Likewise with variability in each echelon I unit, there is also nothing out of control lines, as seen in Figure 10. It shows that the variability of budget achievements in echelon I is not large or homogeneous. 


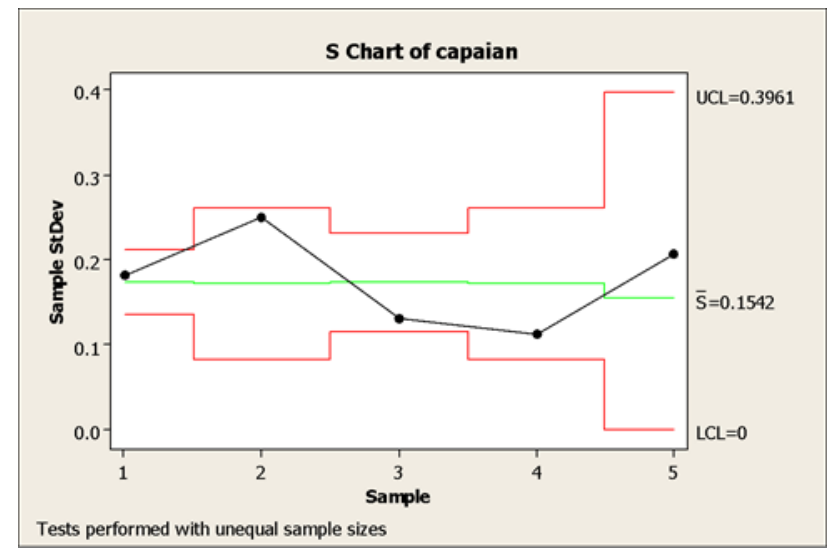

Figure 10. Echelon I Variability Control Chart

To see more detail the commitment of each work unit in each echelon I, it will be seen how the control chart of the average budget achievement and budget variability. The first step is to divide the work units in each echelon I into a subgroup of 3 work units. This will show whether the commitment to achieve the set targets is homogeneous for each echelon I.

Figure 11 shows that there is one observation that comes out of the lower control line, meaning that the work unit's achievements are under control or in other words this work unit has not been able to reach the set target. The realization budget that can be achieved is very low, compared to the set budget target. Observations that come out are observations 1, namely work units that are in the environment of Echelon I " $\mathrm{C}$ ".

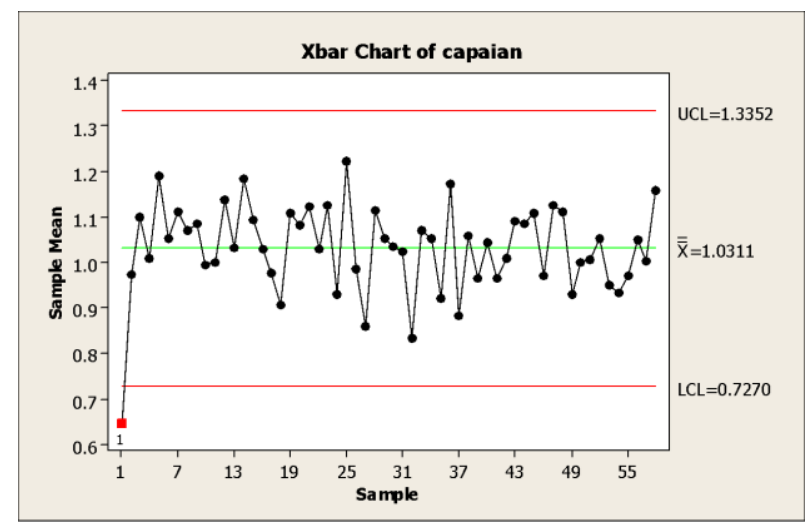

Figure 11. Work Unit Achievement Budget Average Control Chart

There are many controlled observation for the average achievement of the work unit budget meaning that many work units have been able to reach the target. The weakness is if 
there is a work unit with a low achievement average that will be covered by the achievement of a high work unit budget. To see whether in one subgroup is homogeneous or not (budget achievements are not different), it can be seen through the variability of achievements budget in each subgroup in Figure 12.

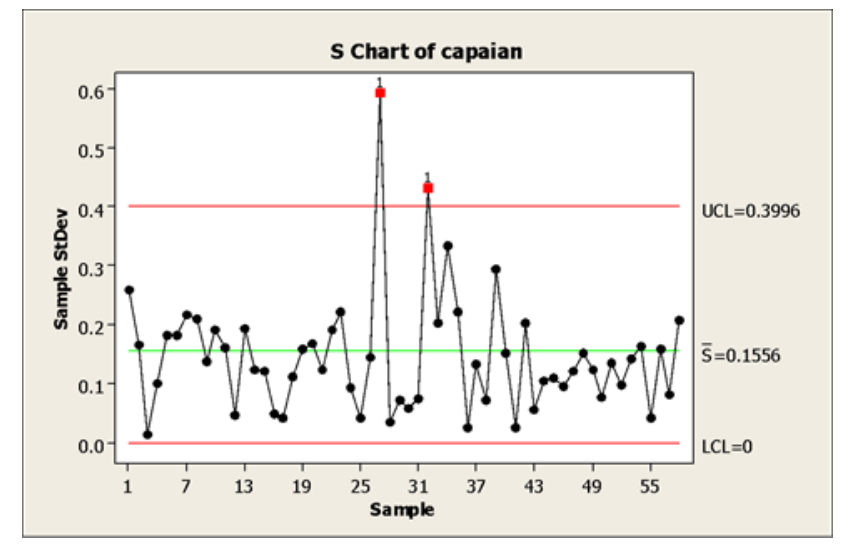

Figure 12. Work Unit Achievement Budget Variability Control Chart

Figure 12 shows that there are two observations coming out of the upper control line. This shows that the subgroup has a large variability in performance budget. The subgroup is a work unit that is in the environment of Echelon I " $\mathrm{C}$ " and Echelon I "D", where there are work units that have very low achievements while the other work units are high. This shows the lack of uniformity of the commitment to achieve the targets set in the echelon I unit.

\section{CONCLUSION}

Based on the analysis and discussion that has been done can be concluded several things, namely:

a. Setting targets for realization budget in a year is set in a top-down manner. The target unit at the highest level will be the same as the target at the lowest level. As for the withdrawal plan budget (prognosis budget) adjusts to the activities of each work unit. The preparation of prognosis is bottom-up.

b. The greater the prognosis set shows that the work unit dares to set challenging targets for the organization. The more challenging the targets are set, the more it will drive the optimal efforts of all organizational resources. 
c. In the preparation of the prognosis, each echelon level has a different prognosis. However, the prognosis can be summarized not to be challenging because the average prognosis set up to the third quarter is in the range of $58.2 \%$.

d. The achievement budget shows the amount of commitment of the work unit to achieve the set targets. If seen from the average achievement of each echelon I, it is known that echelon I units have been able to reach the set targets. However, if seen in more detail in each subgroup in each echelon I there are still work units that have not been able to reach the set targets. This occurs in work units in the environment of Echelon I " $\mathrm{C}$ " and Echelon I "D". There is a work unit that has a very low achievement budget compared to other work units. This is not yet a homogeneous commitment from each work unit to achieve the set targets.

e. The budget policy set in a top-down manner, namely the realization budget target has been fully implemented. All work units from the highest level to the lowest level set the same target for realization budget. This shows the commitment of all work units to achieve the set targets.

f. The achievement budget shows the amount of commitment of the work unit in achieving the set targets. In the Ministry of Finance, echelon I has commitment to achieve the targets which is quite high. However, monitoring and coordination is still needed for the work units up to the lower level because there are still work units that still have not reached the targets they set themselves.

g. Intensive monitoring from the top level will make ownership of the organization at the lower level stronger and is expected to increase efforts to improve its performance. In addition, assistance in case of difficulties is also a positive step to increase commitment to achieving performance targets.

\section{REFFERENCES}

Anthony, R., Govindarjan. (1998). Management Control System, Ninth Edition, New York: McGraw-Hill Companies, inc.

Blocher, Edward J, K.H. Chen dan Thomas W. Lin. (2000). Cost Management: A Strategic Emphasis Edisi Indonesia. Jakarta:Salemba Empat. 
Chndra, Gyan. (1992). The Behavioral Aspect of Budgetingin Sweny and Rachlin, Handbook of Budgeting. New York.

Dongoran, Johnson. "Komitmen Organisasi: Dua Sisi Sebuah Koin.", Jurnal Ekonomi dan Bisnis, Vol. 7 No. 1. Salatiga.

Gibson, Ivncevic and Donnely. (1994). Organisasi (Perilaku, Struktur, dan Proses). Alih Bahasa : Djarkasih Jilid 1 dan 2. Jakarta:Erlangga.

Mowday, J.S Porter, L.W Steers, R.M. (1992). Employee Organization Linkages. New York:Academy Munter.

Paul. (1993). "The Effect of Auditors Ethical Sensitivity.", Journal Behavioral Research in Accounting, Vol. 5.

Steers, R. (1980). Efektifitas Organisasi. Alih Bahasa Magdalena Yamin. Jakarta:Erlangga.

Walpole, Ronald E dan Raymond H. Myers. (1995). Ilmu Peluang dan Statistika untuk Insinyur dan Ilmuwan. Bandung:ITB Bandung.

Welsch, GA Hilton, RW Dan Gordon, P.N. Budgeting : Profit Planing and Control, Fifth Edition. Printice Hall International. 